Literatura y Lingüística $\mathrm{N}^{\circ} 22$

ISSN $0716-5811$ / pp. 59-73

\title{
Néstor García Canclini y la antigua búsqueda de una antropología literaria latinoamericana
}

\author{
Miguel Alvarado Borgoño*
}

\section{Resumen}

En este artículo se realiza una lectura del libro Cortázar, Una Antropología Poética de Néstor García Canclini. Ello con el fin de identificar los puntos de inicio de una antropología literaria como género híbrido. Sostenemos así la independencia de las escrituras experimentales de las antropologías literarias latinoamericanas de las escrituras experimentales desarrolladas en Europa y Norteamérica desde la corriente postmoderna.

Palabras clave: Antropología - literato - poesía - Cortázar

\begin{abstract}
In this article a reading of the book: Cortázar. Una Antropología Poética, it with the purpose of to identify the points of beginning of a literary anthropology like hybrid sort. We base therefore the independence of the experimental writings of the Latin American literary anthropologies of the developed experimental writings on Europe and North America from the postmodern current.
\end{abstract}

Key words: Anthropology - literacy - Cortázar - poetry

* Doctor en Ciencias Humanas, Postdoctorado en Ciencias del Lenguaje. Departamento de Formación Pedagógica. Académico Universidad Metropolitana de Ciencias de la Educación. miguel.alvarado@umce.cl 
Néstor García Canclini y la antigua búsqueda de una antropología literaria latinoamericana /

Miguel Alvarado Borgoño

\section{Cortázar como persecución de la lucidez}

En el estudio de la cultura latinoamericana, en el período que va desde las cadenas golpistas de los sesenta del siglo pasado hasta la actualidad, han sido poco considerados o sencillamente han sido desconocidos los experimentos textuales y plásticos que tuvieron un papel como subversión simbólica y que hoy juegan un rol de cuestionamiento resiliente del orden social capitalista.

En Chile, estos experimentos textuales han tenido caracteres heterogéneos y diversos desde un marcado poder perlocutivo como es el caso de las innovaciones propias de la literatura etnocultural mapuche (Carrasco, 2001) y su vínculo con el actor indígena como sujeto emergente de la acción social, o la escritura centrada en una "experiencia de la corporeidad homosexual" (Sarduy, 1999) como son las obras de autores de Pedro Lemebel y Juan Pablo Sutherland; así también literaturas centradas en el género femenino como las de Diamela Eltit y Carmen Berenguer, o las asociadas a instalaciones audiovisuales experimentales como las de Juan Luís Martínez, o las del grupo CADA (colectivo de arte experimental que desarrolla un conjunto de "acciones de arte" en plena dictadura militar chilena).

En este contexto es que aparece en Chile la Antropología Poética como experimento textual transdisciplinario, siendo el desafío de estos textos su clasificación, ya que desde una primera lectura resultan ambiguos si intentamos encasillarlos en términos de lo que Bajtín entendía como "género discursivo" (Bajtín, 1989). Son todos ellos escritos por profesionales del área de la antropología sociocultural y la arqueología, que recurren a procedimientos textuales muy próximos a los usados por la literatura, particularmente la poesía y la novela. Ello, en tanto en esta Antropología Poética Chilena se reúnen textos donde las textualidades científica y literaria creativamente se ven unidas.

En Chile se ha producido una disputa respecto del origen de la antropología poético/ literaria, en ella participan grupos de antropólogos agrupados bajo el Fondo Matta y que se denominan a sí mismos antropólogos poetas (Alvarado, 2001; 2004; 2006), y los antropólogos literarios, denominación que escogimos para quienes han intentado un cruce entre antropología y literatura, sin reclamar por ello la condición de escritores en su metalengua. La diferencia entre 
unos y otros guarda relación con el interés por las formas estilísticas por parte de los primeros, el deambular entre literatura y antropología por parte de los segundos, son autores como Sonia Montecino, Andrés Recasens, Carlos Piña, que en nuestra opinión aúnan la búsqueda de experimentación textual como recurso para profundizar la propia textualidad antropológica, pero aquello que los distingue es la búsqueda teórica. Pensamos que en este esfuerzo, desde éstos y otros antropólogos literatos (nos referimos a personas más jóvenes que han realizado desde este estilo sus tesis de licenciatura en antropología en Chile o sus primeros trabajos profesionales), es de suma utilidad descubrir el libro: Cortázar, una Antropología Poética de Néstor García Canclini, ello para reconocer las fuentes de sus desvelos, no por que constituya un hipertexto replicado, sino que la pregunta sobre la forma de unir lo literario y lo antropológico resulta aquí antigua y manifiesta, de forma tal que es posible encontrar en este texto un punto de partida para la conformación de una Antropología Literaria, que no se confunda con la literatura ni coquetee permanentemente con la poesía en un guiño de pretensión postmoderna. Más que la defensa o la destrucción del canon antropológico, vemos que la mutación disciplinaria que la Antropología Literaria significa posee fuentes más remotas de lo que sospechamos. Así, nuestro intento no es reconocer un origen sino evidenciar lo permanente de las preguntas.

Cuando Néstor García Canclini habla en su libro Cortázar, una Antropología Poética de antropología no lo hace, ni en el sentido antropológico cultural, ni en el sentido kantiano como una preocupación por el Hombre con mayúscula. No obstante, lo hace ya fuertemente influido por el postestructuralismo y con un fuerte sello existencialista; sorprende que 40 años después este libro convoque la concepción de la antropología heideggereana del hombre "como ser para la muerte" (Heidegger, 1951), que se libera de la angustia frente a su fin inevitable mediante una existencia auténtica, así la persecución de la autenticidad es un esfuerzo escritural que García Canclini adjudica a Cortázar y que, no obstante su adhesión a Michel Foucault en su crítica cultural, no está dado dentro de los postulados del postestructuralismo ni del existencialismo sartreano: en esta obra sobre Cortázar el "hombre" que nos presenta García Canclini no es un "esfuerzo inútil", como tampoco es una entidad muerta o desaparecida en la tundra semiótica del lenguaje. Por el contrario, es desde lo simbólico que el hombre debe ser elaborado o más bien reelaborado, reconstruido (ello desde la lectura que hoy, 2009, hacemos); esta apelación no deja de ser loable en tanto define un camino, que insistimos: hace cuarenta años asume elementos del postestructuralismo pero no hace del nihilismo su fortaleza en la lectura de Cortázar, probablemente de manera indirecta en el humanismo de Sartre encuentra el esfuerzo casi desesperado por reelaborar el concepto de humanidad que le dé un norte específico al sujeto y al objeto de la enunciación; esta tarea aún no resuelta, tema candente de la epistemología y la hermenéutica contemporáneas, requirió de una apelación indirecta a Heidegger y su concepto de autenticidad. 
Néstor García Canclini y la antigua búsqueda de una antropología literaria latinoamericana /

Miguel Alvarado Borgoño

Lo deslumbrante de la obra de García Canclini es que, siendo un individuo de su época y particularmente de su generación, se introdujese en preguntas de las postrimerías del siglo XX y diese atisbos de repuestas que tienen sentido en el siglo XXI, estando su preocupación y centrándose su proposición en la necesidad de una antropología poético - literaria para poder seguir hablando del Hombre en ciencias humanas, ello desde una exégesis de Cortázar, no como coartada, sino como terreno textual concreto desde el cual anclarse y reflexionar. Para ello requiere mostrarnos que verdaderamente existe una Antropología Poética en Cortázar, porque; en su opinión este escritor es capaz de formular un humanismo crítico de la racionalidad moderna, pero que no renuncia a lo que la Ilustración puede aportarle: esto es el esfuerzo emancipatorio de la razón, que no es razón instrumental, sino que por el contrario es la capacidad de discernimiento que se expresa a partir de los símbolos y desde ellos hace posible emprender la construcción del humanismo tan añorado.

García Canclini descubre en Cortázar... una ética y una metafísica nuevas (García Canclini, 1968) esta metafísica es la de los símbolos que superan el nivel del significado definido desde el discurso filosófico de la modernidad, y a su vez esta ética, son quizás el aporte esencial a una antropología poético literaria; el humanismo simbólico de Julio Cortázar, no solamente se atiene a una ética sino que, según García Canclini, habría siempre una búsqueda ética en el fundamento de la textualidad desde los primeros textos hasta los últimos, se trata de una ética laica, de un ser para la muerte heideggereano, que en la autenticidad persigue la lucidez y así dicho lacanianamente: llega la "lucidez del delirio" en la coherencia de acontecimientos narrados a la manera de símbolos: como cualquier etnógrafo, Cortázar no puede narrarlo todo, pero lo que dice es símbolo, cuyo significado es polisémico, pero nunca éticamente relativizante. De su metafísica nos caben dudas, ya que siendo su lectura heideggereana debería hablarse más bien de una ontología; en nuestra interpretación lo vemos como un sentido de trascendencia que más que metafísico sería filosóficamente hablando una mística laica, una mística de lo fantástico.

Cuando García Canclini habla de una...experiencia poética de lo humano (Op. Cit. 16), no solamente da cuenta de la metalengua del escritor Julio Cortázar, sino que define los trazos de algo que en paralelo habían estado desarrollando, en las décadas anteriores, autores como Alfred Metraux, Claude Levis Strauss y Michel Leiris ${ }^{1}$, y que continuará la obra más reciente de Marc Auge; quizás podemos hipotetizar que es el clima intelectual parisino el que hace a Cortázar

1 Este modo de narrar, fiel a la realidad pero simultáneamente cuidadoso en la expresión, posee un contexto pragmático definido desde la tradición novelística francesa y el surrealismo, donde arte y ciencia dialogan desde la década del 20', lo que en opinión de James Clifford guarda relación con la experimentalidad de la literatura francesa de la primera mitad del siglo XX. Ello se expresa en lo que el mismo Clifford ha definido como «el surrealismo etnográfico». Vemos así a Lévi-Strauss dentro de un contexto social y generacional, reunido en torno a la Escuela Normal Superior y al Museo del Hombre, instancias en las cuales confluyen personalidades como Michel Leiris, George Bataille, Jean Paul Sartre, Simone de Beauvoir, Alfred Metraux, y Claude Lévi-Strauss. 
pensar en una Antropología Poética, pero antes de radicarse en Paris, Cortázar ya posee esos trazos; en su primer poemario, escudriñado por García Canclini, casi secreto, firmado por Julios Denis, en una línea formal muy influida por el Borges de los años 30 (quien fue el primero que le publicará posteriormente un cuento en la mítica Revista Sur) Julio Cortázar une la narración de lo fantástico con el detalle minucioso, sonetos clásicos, pero que dan cuenta de un esfuerzo que no es casual y que según García Canclini va a desarrollar en uno de sus libros finales: La vuelta al día en ochenta mundos, la influencia, para García Canclini excesiva de Góngora y Mallarme; experimentalismo y exceso, formas de un barroquismo que luego se fusionarán en su antropología de lo fantástico y simultáneamente de lo humano, un barroquismo casi etnográfico, revelan una experiencia poética de lo humano que levantará lentamente una narración ética y metafísica (para nosotros más bien mística), cuyo objetivo es, para García Canclini, un intento antropológico, no filosófico, diríamos nosotros semiológico, en el cual intenta unir el significado con el significante, pero ello recurriendo a un autor que recién hoy la antropología reconoce, el lector; se trata de un humanismo que semióticamente se llena con el significante abierto a las experiencias (dicho gadamereanamente) de la tradición del lector. Este humanismo se radicaliza para García Canclini en la apelación al lector, quien completa la narración.

\section{De los monstruos}

Para García Canclini, la definición de lo poético no hace referencia a la producción de textos que se ubiquen tipológicamente en el género de la poesía, en su concepción aristotélica, son aquello que apela a lo que se denomina como expresión poética; en nuestra lectura de Julio Cortazar (1914-1984) desde García Canclini, hablaríamos más bien de un enunciado poético que se nutre de formas que solamente pueden ser halladas en la poesía pero que Cortázar ubicó en el ámbito de la prosa, la poesía se da en un sentido de carácter estilístico y no tipológico, donde en particular el lector realiza una mimesis desde formas expresivas en la cuales los significantes son abstractos y ambiguos, y la poesía de Cortázar, o más bien su poeticidad, se concentra en su apelación al lector, sin el lector no existiría esta poética de Cortázar, no habría una Antropología Poética. Quizás una de sus formas poéticas más característica sea la de los monstruos, desde el tigre hasta el minotauro, con ello apela a los más recónditos vericuetos del inconsciente: ellos son ampliamente polisémicos, monstruos en tanto deliberadamente sin forma definida son herramientas semánticas, donde, sin mayor estridencia, tanto para García Canclini como para nosotros se encuentra la genialidad de Cortázar, ello en tanto nos permite unir lo narrativo cotidiano con lo fantástico, rescatando justamente lo poético que estas figuras- personajes poseen.

El exorcismo de la bestia se realiza primero desde el rito de la palabra y luego este rito tiene una continuidad en la lectura comprensiva. En el Cortázar 
Néstor García Canclini y la antigua búsqueda de una antropología literaria latinoamericana /

Miguel Alvarado Borgoño

de García Canclini los monstruos no son seres extraordinarios, sino que resultan ser los límites cotidianos que se van sorteando, en muchos casos esquivando; en la obra de Cortázar, hay un amoroso acto de matar al minotauro, pero el minotauro no tiene una definición isomórfica que vincule lenguaje, pensamiento y realidad; en su genialidad, según García Canclini, Cortázar es capaz desde un lenguaje simbólico (argentino o francés) muy cotidiano inmensamente comprensible, el lenguaje donde operan los símbolos del día a día, de dar cuenta de los modos terroríficos que asolan el inconciente y que determinan la conducta, como en la caja negra conductista: esos monstruos, esos seres fantásticos no son posibles de describir claramente, pero sí se puede narrar la conducta que desarrollan los actores frente a ellos.

He aquí una forma de lo que denominaríamos una "etnografía de lo monstruoso", en el sentido de una etnografía delirante de lo fantástico...el orden sofocante (García Canclini, Op. Cit. 25) al que García Canclini va a referirse, ese orden sofocante de la opacidad de los cotidianos. ¿Qué enseña esto a la antropología sociocultural? Nos enseña hace cuarenta años la superación de la narración de lo evidente en las relaciones sociales, del temor del niño, en el viaje en tranvía o al tigre, de la pareja del cuento en Casa tomada. García Canclini descubre una narración verdaderamente extraordinaria para la época, una etnografía que asume al lector (aunque García Canclini nunca usa el término etnografía) y por otro lado asume los factores inconcientes de la conducta del actor, por ello es una narración que intenta "barajar la totalidad", describe una conducta o una relación social, invita a dar un significado a los monstruos como seres simbólicos, de los cuales da algunas pistas o señales, hasta que el círculo compresivo se completa con la lectura, por ello es una etnografía en la que el lector es plenamente integrado y en la cual lo que se narra no es la conducta ni la relación social, sino las formas simbólicas del propio lector que pueden ser identificadas en sus diversos significados en el acto literario y antropológico de la lectura.

No hay en Julio Cortázar, según García Canclini, una idolatría respecto de los temores, estos son parte de lo que debe ser narrado: el laberinto, por ejemplo. Es parte del peregrinaje etnográfico, así el antropólogo literato que va perfilando García Canclini es un ser que no cae en el ocultamiento, en lo que psicoanalíticamente es la introyección del trauma, ello porque realiza una Antropología Literaria no literatosa, lo humano es por tanto: la capacidad de vivenciar a los monstruos, narrar algunas de sus características y desarrollar una instalación capaz de ser rellenada por el lector, se trata de un peregrinaje etnográfico, ello en cada relato se hace presente en alguna medida, por Ej. La vuelta al mundo en ochenta días es un peregrinaje etnográfico donde narrar lo fantástico no es referirse a otras realidades, sino intentar poner al alcance del lector toda la realidad, incluso aquella que le es propia al lector individuo y sus procesos inconscientes.

En el plano justamente del inconsciente, para García Canclini hay en Cortázar una posición comprensible apropiada, pero que no siempre es evidente:

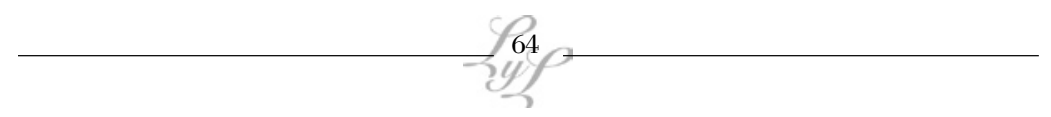


si su intención desde una Antropología Poética es narrar esa verdad compleja que es la de lo visible significante de lo invisible: lo que se narra en definitiva es el inconsciente colectivo, sus monstruos y seres fantásticos y completará esta narración con la mimesis del lector que se identifica en tanto es él quien completa la narración, dice García Canclini. Para Cortázar lo monstruoso es justamente lo que se custodia, un nexo tradicionalmente no narrado entre terror y deseo, aunque por momentos se evada en la enunciación a los monstruos éstos están curiosamente en el ámbito de lo inconscientemente deseado, son Godot, lo esperado. De la antropología clásica podría decirse lo mismo, pero exteriormente manifestado de otra forma: brujería, oráculos, maldiciones, encantos, demonios, duendes, ángeles, etc. son parte fundamental de la narración de cualquier etnógrafo clásico, de la misma manera si no se convive con lo fantástico la realidad simplemente no podría existir porque ello significaría mentes limpias y las mentes limpias están vacías, no existen seres humanos con mentes vacías, narrar lo fantástico consiste en narrar lo real y para García Canclini ... las estructuras trazadas por la razón (Op. cit. 29) y con ello se refiere a la razón occidental moderna, intenta negar la presencia del deseo como instancia de generación de lo real, un deseo que no solamente guarda relación con el goce, sino con el deseo de lo misterioso que devela una dimensión del sujeto, su deseo por lo monstruoso es su deseo por aquello en su inconsciente que lo hace humano en un sentido que supera al discurso filosófico de la modernidad y su suposición de identidad entre realidad y razón. Si hablamos aquí de antropología (de la de Cortázar en 1968 y la nuestra en 2009) lo hacemos en los términos de un ser humano con la cabeza llena de su fantasía, esa fantasía puede ser gozosa o monstruosa, o ambas cosas al mismo tiempo, como el niño que frente a una película de terror siente repulsión y al mismo tiempo le es imposible dejar de mirar.

\section{Una antropología de lo absurdo}

Muy en el contexto del clima de época, pero no por ello desfasado para nuestra época, vemos la presencia de lo absurdo (probablemente en relación directa con el teatro existencialista, el teatro del absurdo que decanta luego en el teatro pánico) ¿cómo se estructura una Antropología Literaria de lo absurdo? Primero que nada rompiendo la confianza de la ciencia social fundamentada en la identidad entre realidad y razón: no solamente la historia sorprende, también lo cotidiano, y la antropología de Cortázar es una antropología de lo cotidiano para García Canclini, pero lo cotidiano al estar inundado por lo fantástico es también una realidad teñida por el absurdo, un absurdo que va desde lo ilógico hasta la locura.

La gran limitante de la antropología científica contemporánea ha sido el intento poco afortunado de establecer regularidades, el paso de lo etnológico a la debilidad del orden racional, con la ambición de lo teórico desde una perspectiva epistemológica nomológica, se ven confrontadas con el absurdo de lo 
Néstor García Canclini y la antigua búsqueda de una antropología literaria latinoamericana /

Miguel Alvarado Borgoño

cotidiano; nos referimos al momento cuando la antropología clásica intentaba desde una perspectiva ahistórica dar cuenta de la forma estructural de un sistema social, al cual se le atribuyen regularidades, lo que Radcliffe Brown llamó funcionalidad estructural, lo que no es otra cosa que un deseo que lo racional sea real, y que por añadidura sea posible desentrañar los vínculos entre lo individual y lo colectivo. El gran fracaso ha consistido en la paradoja de que la única regularidad encontrada sea el tabú del incesto, y que al narrar de una otra manera el antropólogo se tope con aquello que le aterra, esto es el absurdo: a Cortázar, según García Canclini, el absurdo no le aterra sino que lo impulsa. García Canclini habla de los riesgos de la lucidez (Op.cit. 44) pero frente a la imposibilidad de ver el futuro, y a la conciencia del absurdo del presente, todo esto proyectado en la narración, en que el yo es siempre otro, en la narración del pasado la lucidez del relato etnográfico es más bien una forma de eludir la angustia existencial frente al absurdo. Cuanto bien le hubiera hecho a la antropología latinoamericana en su proceso de conformación entender como lo propuso García Canclini:, a la manera de Cortázar, asumir la imposibilidad de la lucidez, entendiendo por lucidez la narración de lo sensible a nivel especialmente sincrónico.

La antropología de Cortázar es delirante, en tanto todo delirio tiene una coherencia según Lacan, pero esa coherencia no es la de la razón occidental y menos la de la ciencia tradicional. Cortázar, en la interpretación de García Canclini, es un antropólogo de lo no lúcido, diríamos hoy "extático", no porque desvaríe de manera incoherente sino por que verá: escenarios, situaciones, relaciones, en que lo fantástico se ensambla con lo que habitualmente consideramos lo real; el narrador que ve un batracio mexicano exótico: el Oxolotl, o el motorista que sufre un accidente en La noche boca arriba, transvertidos en su propia fantasía, es una realidad delirante pero no por eso incoherente, lo real no es lo que parece, en tanto lo simbólico nos hace traspasar como lectores al plano de lo imaginario, dándonos una antropología que narra otra realidad, o , dicho de otra manera, una realidad más completa en la que el lector participa.

\section{Los cronopios y el amor de Cortázar, una búsqueda de la autenticidad}

En Historias de cronopios y de famas (1962) se devela una "ideología de la cotidianeidad" en Cortázar, como sistema de valores que asumen una postura frente al bien y al mal en la experiencia de la vida pero desde la personificación y las metáforas, pero en el relato de García Canclini es una narración que desde el absurdo lleva una contraposición con lo que habitualmente se entiende por lo real, lo real en términos de Foucault son los órdenes discursivos en los que la estructura social se apoya para denegar o conferir verdad, como modo concreto de conferir poder. Esta contraposición entre las famas superficiales y evidentes y los cronópios absurdos y altruistas, se nos presenta, lúdico, lo adolescente 
es propio de los cronópios, Cortázar no habla de irresponsabilidad ya que no habla desde el orden cultural.

La subversión respecto de los patrones de conducta clásicos y normados, es en Cortázar, según García Canclini, el modo en que se desarrollan los ritos y se juega más allá de los ritos mismos; al igual que en la polaridad entre amor y usura que realiza Ezra Pound en sus Cantos, hay una polaridad entre la apelación a los órdenes discursivos, a lo socialmente verdadero definido según la forma en que en cada contexto se organiza el poder, y los cronopios que subvierten los órdenes discursivos: el amor de Cortázar está representado por los cronopios, por la adolescencia, por los ritos subvertidos, ello en la inocencia y el altruismo. La palabra amor es polisémica en nuestra cultura, puede significar dependencia, pasión, lujuria, ternura, compromiso, afectividad, etc. En Cortázar el acercamiento a esta ternura desencadenada que podríamos interpretar de manera amplia como la experiencia del amor, es un acercamiento oblicuo, que rompe con la definición precisa desde una ruptura con los ritos amorosos... no te regalan un reloj, tú eres el regalo (Op. Cit. Pág. 67), hay necesidad de subversión frente las formas represivas, ello desde la ternura, la caridad y la disociación de las formas de relación social convencional.

En Cortázar el amor es todas esas cosas juntas; no te regalan un reloj, tú eres el regalo: si en la medida del tiempo en la edad media el tiempo no era una cronología en el sentido contemporáneo, como tampoco en las culturas aborígenes, el tiempo es el de los ciclos de la naturaleza. El reloj es un texto que define nuestra vida; así el amor de Cortázar representado por el cronópios, intenta superar el orden del reloj como texto regulatorio, y se aboca a aquello que es propio de los niños: el juego, pero ¿cuál es la diferencia entre juego y rito? no es la conducta misma, sino el modo en que las relaciones de poder operan, para convertir lo gozoso en algo obligatorio.

Narrar el rito como estructuración de la conducta y olvidar el juego es negar la posibilidad de disidencia, pero, para García Canclini, Cortázar propone una suerte de "antropología del juego" donde el juego es lo propio del niño, pero también lo es solapadamente de los adultos, una necesidad negada, pero que aparece bajo la forma de la irracionalidad; si el juego es delirante tiene un orden, y ese orden oculto es objeto de la Antropología Poética de Julio Cortázar. La autenticidad se encuentra justamente en este amor, como tipo ideal delirante representado por el cronopio, todo aquello que restringe la realidad a lo evidente, en el contexto de la racionalidad técnica se convierte en un algo inauténtico, el valor del "ser para la muerte" heideggereano, no es el de un oscurantismo casi espectral, es una opción lúdica para pasar del rito de la conducta a la subversión por medio del rito de la palabra, es una racionalidad que no es de este mundo.

Más que seres fantásticos, los cronopios y las famas son seres "tipos ideales" en un sentido webereano, tipos humanos en los que Cortázar deposita su amor, la materialización de lo idealizado como única verdad. El mundo 
Néstor García Canclini y la antigua búsqueda de una antropología literaria latinoamericana /

Miguel Alvarado Borgoño

material despojado de fantasía, es aquello que para Pound significa, en una equivalencia de los campos semánticos, la usura: en Cortázar y Pound, escritores de posiciones ideológicas radicalmente distintas, hay una crítica de la modernidad y sus relaciones de producción capitalistas, que no dan pie a lo fantástico en la cotidianeidad. La administración mecánica de lo fantástico que va desde el cine hasta el manejo de las vías de información están justamente en el eje de la inautenticidad que Pound y Cortázar denuncian, lo fantástico no es lo irreal, lo fantástico en la lectura de García Canclini es para Cortázar la liberación autónoma de lo fantástico, y por ello de lo fantasioso y delirante, ello en un proceso que es siempre la liberación de los órdenes del discurso; si lo fantástico puede ser manipulado y por tanto convertirse en un instrumento de dominación, la fantasía no es ni entretenimiento ni ficción manipulada, es la liberación de monstruos amables o rabiosos, pero que son parte del discurso de la conciencia del lector, en el plano de sus deseos y sus temores más internos, por ello lo fantástico puede ser un instrumento emancipatorio: en ello hay una, ética de la liberación humana por medio de lo fantástico, así la Antropología Poética de Cortázar se transforma en un oficio de narración emancipatorio, el cual tiene como fin superar el malestar cultural; el antropólogo que sueña Cortázar es en García Canclini un antropólogo que abarca una realidad en una totalidad, la cual al completarse se convierte en un instrumento emancipatorio de las formas de dominación simbólica de la cultura moderna, los símbolos se subvierten y la semiósis de los lectores es la continuación de la línea de montaje de su antropología poético/ literaria, la que no se centra en la cultura, sino en la liberación de las formas de dominación que en lenguaje y por que ello en los símbolos, la cultura porta y de los cuales es deudora.

\section{El minotauro es nuestro hermano}

Néstor García Canclini en el capítulo final de este libro, titulado "La casa del hombre", define las bases de su Antropología Literaria no como antropología filosófica de la literatura o antropología cultural preocupada de lo literario, sino como una Antropología Literaria que desde una concepción heideggereana une el habitar con el poetizar, determinando una antropología que requiere del texto, considerado no solamente como producto del contexto, la idea del pensar poetizante de Heidegger se hace vida en Canclini.

El Cortázar de García Canclini nos ubica en la exacta realidad. En su esfuerzo por completar aquello que Gadamer llamara fusión de horizontes, García Canclini destaca esta invitación al lector que Cortázar realiza, no solamente como una estrategia narrativa sino como un modo de construir un texto que se desdobla sobre otro texto, pero ello desde una comprensión en la narración de la realidad del hombre, aquello que en antropología tradicional se ha denominado como los estilos de vida, es justamente aquello que el texto constituye; en la concepción de García Canclini, el texto de Cortázar ni siquiera recurre a una coartada religiosa para deslizar lo mágico: lo imaginario es un componente de 
lo real. Por lo tanto, los estilos de vida requerirán para ser narrados de la introducción de la dimensión de lo imaginario, no como falsa conciencia sino como una dimensión olvidada y develada de la realidad, que, unida a lo simbólico, configuran la totalidad de lo real cuando se depositan en los ojos del lector en el acto ritual por excelencia, el rito final: el acto de leer.

Sin duda, desde la antropología social de Frazer, Durkheim, Marx o Freud, que introducía lo simbólico de manera descarnada en una reflexión que carecía de fuentes etnográficas, se ha planteado que el aporte del funcionalismo antropológico es justamente el "estar allî" de Bronislaw Malinowski, es decir, la exigencia metodológica y ética de un trabajo etnográfico de campo intensivo que entregue sustento empírico a la reflexión antropológica; sin embargo, la relación entre función y estructura es mirada desde un sesgo amoral que sitúa al etnógrafo como un observador presumiblemente objetivo, la historia posterior de la antropología desde el cognitivismo, hasta la antropología postmoderna, se ha dedicado a cuestionar esta idea de la objetividad como espejismo de pureza. No obstante, aquello que se cuestiona no es el trabajo de campo como realización y experiencia con sentido autónomo; es más, la antropología de la segunda mitad del siglo XX se ha enfrascado, en muchos casos, en un tipo de trabajo de campo que resulta en una casuística, la que, al no hacer posible la supuesta comparación etnológica no ha respondido a la imaginación nomológica de acumular verdad desde la comparación; así es como recién en la década de los ochenta, la antropología a nivel universal llega a la narración como preocupación básica. Sin embargo ipor qué un destacado académico como Néstor García Canclini, que ha sido uno de los grandes teóricos de la antropología latinoamericana, no fue leído en este libro puntual por los antropólogos hace cuarenta años, sino que fue alabado exclusivamente por los estudiosos de la ciencia literaria? La separación en compartimientos disciplinarios es quizás uno de los peores efectos que la copia fiel respecto de los ejes centrales se hace en las ciencias sociales y humanas; la última moda de París o de Nueva York es absorbida con fruición por los científicos y humanistas del continente. El eurocentrismo que luego pasa a constituir con Estados Unidos una relación centro-periferia coloniza el pensamiento y coloniza también el pensamiento respecto del pensamiento; este libro de García Canclini sobre Cortázar es una obra de juventud, escrita por un joven profesor de literatura argentino, que con el tiempo se hará antropólogo. La obra fue admirada en su momento; no podemos saber hasta que punto comprendida, pero respecto de ella hubo silencio y desconocimiento en las ciencias humanas y sociales, la antropología argentina y latinoamericana no hicieron ni mención de este aporte; ello básicamente desde un punto ciego surgido junto a los resquemores de los compartimientos disciplinarios.

Difícilmente en la década de los 60 donde el estructuralismo funcionalista dominaba las ciencias sociales y donde se suponía que el cambio cultural estaba supeditado al cambio social, podría haberse valorado una obra que introdujera en la antropología el papel de lo imaginario. Ello resulta curioso si la antropología no solamente estudia la vida material sino la vida mental, pero esa vida 
Néstor García Canclini y la antigua búsqueda de una antropología literaria latinoamericana /

Miguel Alvarado Borgoño

mental estudiada era vista como el producto o de relaciones productivas o de relaciones sociales a secas, pero nunca como un eje motor de las formas que los estilos de vida irán adquiriendo.

El minotauro no podía ser nuestro hermano ya que solamente existía en el plano de nuestras pesadillas. Cortázar hace una "etnografía del delirio" desde una poética al alcance de cualquier lector interesado, García Canclini convierte esa etnografía delirante en un camino posible para nuestra antropología latinoamericana, la lectura de este libro es, por tanto, un acto de descolonización de nuestra praxis disciplinaria en antropología. No se trata de un esfuerzo interdisciplinario sino transdisciplinario, lo importante no es si aquello que descubre García Canclini en Cortázar es antropología social o teoría literaria, lo importante es reconocer el modo en que se puede desde aquí definir un pensamiento situado que, a nivel epistemológico, teórico e incluso metodológico aporte al quehacer de las ciencias humanas y sociales; es la introducción de lo imaginario en la pregunta ontológica por el observador, la clave de una antropología poético literaria que representa la base de toda posible Antropología Literaria en nuestro continente. En el capítulo titulado Escribir la literatura, García Canclini realiza un ejercicio de reflexión que por momentos se aleja de su objeto, la obra de Cortázar y más bien lo vemos como una reflexión sobre su propia práctica escritural, y allí descubrimos el uso de dos herramientas que él extrae de la estética literaria y que son fundamentales para una Antropología Literaria: discontinuidad y metalenguaje: en Antropología Literaria el metalenguaje es justamente el modo en que el antropólogo se va preguntado sobre su propia escritura y por ello va desarrollando un discurso sobre su discurso, la discontinuidad saca a la antropología de la opacidad de la historicidad y la remite al plano de la memoria, la memoria es y debe ser discontinua, ello porque ninguna memoria puede reconstruir el pasado minuto a minuto, segundo a segundo, porque requiere de criterios de distinción, es decir, de selección sintagmática que distinga aquello atingente. No obstante, el discurso de quien lee una novela o del antropólogo que narra un rito debe poseer criterios para seleccionar lo leído u observado y ordenarlo en una secuencia paradigmática, esos criterios de selección requieren de un metalenguaje: es justamente en el metalenguaje donde está la esencia de una Antropología Literaria, en la capacidad de reflexionar sobre su práctica, y García Canclini incluso lo plantea, desde un horizonte ético, la narración reestructura desde una metalengua y justamente allí está la fuente de la posibilidad latinoamericana de hacer una teoría auténticamente situada respecto de la cultura.

\section{Conclusiones}

Este artículo resulta de una lectura culpable, ella se corresponde con el deseo de demostrar la existencia de un antropología literaria y también señalar la originalidad de esta, su principal sentido resulta de este esfuerzo, el que se ve unido a una crítica postcolonial de algunas formas de antropología poética que 
intentan vincular al postmodernismo los experimentos textuales de la antropología chilena y latinoamericana.

Nuestra hipótesis consiste en la afirmación de la existencia de una antropología literaria latinoamericana desde hace más de cuatro décadas, y nuestro objetivo es dar cuenta de una forma escritural, la cual bajo la cobertura de la ciencia y de la literatura ha ido generando una forma textual original, aunque difusa hasta hoy. Sostenemos que Néstor García Canclini es uno de los primeros exponentes de una Antropología Literaria Chilena y Latinoamericana; así afirmamos que existe desde hace más de cuatro décadas un género discursivo híbrido aún no lo suficientemente estudiado, al que hemos denominado como Antropología Literaria, el cual constituye una "mutación disciplinaria" (Carrasco, 2001) desde el campo científico al literario, propiciada por la literatura como fuente metalingüística. Así, este ensayo da cuenta del inicio del desarrollo de una forma textual aún no reconocida plenamente por la academia, pero que resulta un terreno fértil para especialistas en metateoría, historia de la ciencia y estudiosos de la literatura, entre otros.

Sin embargo, el intento de reconocer, descubrir, identificar genealogías, guarda, sin duda, una relación con la necesidad de reconocer un orden en lo real: sea cual sea esa la concepción de lo real que se baraje o se intuya. Probablemente es por ello que en el plano de los estudios de la cultura y especialmente en las ciencias preocupadas de la significación sean tan populares los conceptos tales como polifonía, intertextualidad, palimpsesto. etc. Nuestra aproximación al libro Cortázar. Una Antropología Poética no surge de una búsqueda genealógica, ya que asumimos que ello estaría lleno de eslabones perdidos, a la manera del romanticismo darwiniano, particularmente para la antropología social misma; siendo curiosamente este libro probablemente el primer esfuerzo sistemático por acercarse a este texto desde un horizonte antropológico interdisciplinario. No obstante, este libro ha sido objeto de una admiración irrestricta, y lo que es más importante, de una lectura sistemática por parte de autores fundamentales de la historia y la teoría literaria contemporánea, hoy descubrimos en este texto de hace cuarenta años preguntas que siguen sin respuestas pero que en 1968 no eran siquiera aún suma de aseveraciones e interrogantes, formuladas en el horizonte europeo, antes de los estudios culturales, de las escrituras postcoloniales o hermenéutico culturales, Néstor García Canclini diseñó una formulación que desde el horizonte de los estudios literarios se proyectó hacia una concepción de lo real, donde lo real es una suma de significaciones, semiconscientes o francamente inconscientes, que escapan a la lógica positivista de la comprobación empírica, o a la lógica cartesiana de un pensamiento lógico para consigo mismo; García Canclini utiliza a Cortázar, escritor axial de ese momento que unía compromiso político con la fantasía más alucinada, para generar un texto que hoy redescubrimos, primero por que representa un conjunto de incertidumbres que desde hace cuarenta años nos rondan, y también porque proporciona algunas respuestas que sin duda son de utilidad heurística en el proceso de conformación y reconocimiento social de una antropología literaria. 
Néstor García Canclini y la antigua búsqueda de una antropología literaria latinoamericana /

Miguel Alvarado Borgoño

El aporte de García Canclini es innegable para el estudio de la cultura latinoamericana, desde su obra Las culturas populares en el capitalismo (1982), libro que lo hizo internacionalmente conocido, hasta su texto Culturas hibridas. Estrategias para entrar y salir de la modernidad (1990), que generó una alternativa frente al concepto de sincretismo latinoamericano, el cual estaba excesivamente unido, en su opinión, al plano de las formas religiosas; no obstante, la obra de juventud que aquí analizamos, que data del año 1968, parece huérfana, o a lo menos aislada del resto de su producción. Es posible pensar que se trata de una obra cuyo fin era cimentar la carrera de un estudioso de la literatura que luego se convierte en antropólogo, pero ello es reproducir el estancamiento en compartimientos disciplinarios que tanto daño ha hecho a las ciencias humanas latinoamericanas. Por el contrario, hay aquí una serie de señales para una ruta que desembocará en sus obras posteriores; pero, para nosotros, lo fundamental en lo referido al concepto de realidad y donde lo imaginario y lo fantástico no se separan de la realidad, como esencia del texto de Cortázar para García Canclini, sino que forman parte de ella, asumiendo que muy cartesianamente, aunque parezca contradictorio, es desde el pensamiento desde donde es posible dar cuenta de lo real, pero un pensamiento que captura destellos del inconsciente y desde allí organiza la cosmovisión de los personajes de Cortázar.

La homología entre pensamiento y realidad no se da en un terreno de certidumbres lógicas y empíricas, sino en el desdoblamiento desde la narración de lo cotidiano hacia la sorpresa: García Canclini descubre que en lo profundo Cortázar es un gran realista, pero un realista de un tipo que solamente una antropología poético literaria es capaz de contener. Independientemente del boom de la literatura latinoamericana, y de la disputa con José María Arguedas respecto de si acaso es posible seguir siendo latinoamericano en Paris y escribir superando esta disyuntiva, en Cortázar, ya sea en Buenos Aires o en Europa, el realismo incluye, baraja y asume una dimensión de lo real donde se adicionan elementos: lo fantástico, sea la crueldad como teatro de sombras o sea lo onírico, incluso la duda, la falta de caracterización de un personaje o de una situación convierten a su narración en una narración prototípica que supera el plano de la realidad etnográfica clásica para ser una suerte de estereotipos de lo real, donde lo fantástico es la sumatoria de experiencia e imaginación, convertida esta sumatoria tanto en vivencia como en recuerdo, pasado presente y futuro, como también lo posible y lo imaginario, son parte de esa concepción de lo real de Cortázar que caracterizada por García Canclini aún nos deslumbra.

García Canclini dejó pistas que no siempre fueron seguidas, pero que hoy pueden conformar las bases de una antropología literaria: lo fantástico como una dimensión de lo real explorable en el examen de lo simbólico, una ética de la narración que supera lo religioso pero da cuenta de una mística de la mirada antropológica, y la conjunción entre los ritos de la mirada, la escritura y la lectura para rehacer lo real en cada interpretación de lo que el antropólogo aporta, ello cuando el antropólogo asume que su oficio es ante todo la escritura. 


\section{Bibliografía}

\section{Fuente Primaria}

García Canclini, N. (1968). Cortázar. Una Antropología Poética. Editorial Nova: Buenos Aires.

\section{Fuentes secundarias}

Alvarado, M. (2001). La Antropología Poética Chilena como textualidad híbrida. Tesis para optar al grado de Doctor en Ciencias Humanas. Valdivia: Universidad Austral de Chile.

Alvarado, M. (2004). Ensayos de análisis cultural: aportes sobre la conformación del discurso en torno a la diversidad en las ciencias humanas y sociales latinoamericanas. Valparaíso: Ediciones Universidad de Playa Ancha.

Alvarado, M. (2006). El Espejo Rápido. Interculturalidad y prevaricaciones discursivas. Valparaíso: Editorial Putángeles.

Bajtín, M. (1989). Estética de la creación verbal. México: Siglo XXI.

Carrasco, I. et al. (2001). Interdisciplinariedad, interculturalidad y canon en la poesía chilena e hispanoamericana actual. Proyecto aprobado Concurso regular del Fondo Nacional de Ciencia y Tecnología. Número 1010747.

Cortázar, J. (1962). Historias de cronopios y de famas. Madrid: Alfaguara

García Canclini, N. (1982). Las culturas populares en el capitalismo. México: Editorial Nueva Imagen.

García Canclini, N. (1990). Culturas híbridas. Estrategias para entrar y salir de la modernidad. México: Grijalbo.

Sarduy, Severo. (1999). "Escrito sobre un cuerpo". En Obra Completa. Madrid: Allca XX. 